\title{
INTEGRAÇÃO DOCENTE-ASSISTENCIAL: UM ESTUDO DE CASO*
}

\author{
TEACHING-WELFARE INTEGRATION: A CASE STUDY
}

Agnes Olschowsky** Graciette Borges da Silva***

\begin{abstract}
OLSCHOWSKY, A ; SILVA, G. B. Integração Docente-Assistencial: um estudo de caso Rev.Esc.Enf.USP,
\end{abstract} v. 34, n. 2, p. 128-37, jun. 2000.

\section{RESUMO}

O objeto de estudo deste trabalho é o processo de integração docente-assistencial entre a Escola de Enfermagem da Universidade Federal do Rio Grande do Sul e o Hospital de Clínicas de Porto Alegre, enfocando os atores envolvidos e a sua prática histórica concreta. Pretende-se conhecer a dinâmica das relações do referido processo, entendendo-o como um trabalho coletivo que resulta de transformações históricas e sociais. A dicotomia inter-institucional transparece como regra, desencadeando uma problemática de integração. A IDA existente não é harmônica, mas as relações de força que a integram devem ser aproveitadas como instrumento para sua ação e transformação, definindo a construção/reconstrução de novas alternativas.

PALAVRAS-CHAVE: Integração docente-assistencial.

\section{ABSTRACT}

The teaching-welfare integration process (TWI) between the "Escola de Enfermagem da Universidade Federal do Rio Grande do Sul" and the "Hospital de Clinicas de Porto Alegre" is this work's object of study focusing the actors in it and its concrete historical practice. The intention is that of knowing the dynamics of the process relationships, understanding it is a collective work as the result of historical and social changings. The inter-institutional dychotomy becomes evident as a rule, unleashing an integration issue. The existing TWI is not a concordant one but its integrating power connections must be used as a motive for its action and transformation, defining the making and re/making of new alternatives.

KEYWORDS: Teaching care integration.

\section{INTRODUÇÃO}

Este estudo relaciona-se à nossa experiência profissional de docente e enfermeira psiquiátrica, na Escola de Enfermagem da Universidade Federal do Rio Grande do Sul (EEUFRGS) e no Hospital de Clínicas de Porto Alegre (HCPA). A EEUFRGS utiliza a estrutura do HCPA para a maioria de suas atividades de ensino, pesquisa, assistência, sendo que a coordenação do serviço de enfermagem é feita pelos enfermeiros-docentes da Escola.

Viamos, inicialmente, essa presença da EEUFRGS no hospital como um fator que contribuía para a prática hospitalar de enfermagem, qualificando-a e atenuando as dificuldades de "indefinição de papéis, de desprestígio e da falta de autonomia dos enfermeiros assistenciais". Ao mesmo tempo, percebíamos dificuldades nessa relação: os docentes eram vistos como aqueles que detinham o saber e o poder, como empecilhos na ascensão administrativa dos enfermeiros (HOSPITAL DE CLÍNICAS DE PORTO ALEGRE, 1975), visitantes que utilizavam a área do hospital para o ensino e atrapalhavam a rotina do serviço.

Em 1990, participamos de um grupo de trabalho que elaborava uma proposta para ativar a integração docente-assistencial entre EE-HCPA, tendo como objetivo organizar a relação das duas

\footnotetext{
*Resumo da Dissertação apresentada ao Programa de Mestrado de Enfermagem Psiquiátrica e Ciências Humanas da EERP-USP, 1995. **Enfermeira, Professora Assistente da Universidade Federal do Rio Grande do Sul, Doutoranda da EEUSP.

***Professora Doutora do Departamento de Enfermagem Psiquiátrica e Ciências Humanas da EERP-USP.

1SILVA (1986: 128) cita que, na perspectiva dos enfermeiros, constituem seus problemas principais: a indefinição de papéis, o desprestígio e a falta de autonomia.
} 
instituições que, nesse período, encontrava-se mais fragilizada e menos legitimada devido à divisão dos docentes e enfermeiros e aos conflitos de poder entre eles.

Definimos, então, como objeto de estudo de nosso mestrado, concluído em 1996, o processo de integração docente-assistencial EE-HCPA, enfocando os atores envolvidos e a sua prática concreta, tendo por pressuposto que a participação dos enfermeirosdocentes da EE no HCPA contribuía para uma autodeterminação, definição e interpretação da enfermagem, introduzindo novos procedimentos técnicos, melhoria da qualidade na assistência de enfermagem prestada nesse hospital, possibilitando uma política de planejamento, supervisão e avaliação sem a intervenção de outros profissionais.

Entretanto, constatamos que, mesmo com os avanços alcançados, essa relação tem sido vivida com conflitos entre enfermeiros-docentes e enfermeiros-assistenciais, configurando uma divisão técnica do trabalho que parece oferecer privilégios aos docentes, enquanto os enfermeiros-assistenciais executam suas atividades controladas por normas e rotinas (estabelecidas pela EE e HCPA), tendo sua autoridade reduzida ao âmbito da coordenação da assistência prestada nas unidades de internação. Surge, assim, disputa de poder entre ambos os grupos por uma posição supostamente mais privilegiada e de maior status, articulando-se uma relação de domínio e resistência.

Essa disputa pelo poder, por um lado, reveste-se de uma enfermagem qualificada e eficaz, sendo referência para a região sul, pois os enfermeiros-docentes e os assistenciais querem mostrar sua competência, associada com a vinculação do hospital à universidade, contribuindo na difusão de novas técnicas e conhecimentos de saúde. Ao mesmo tempo, essa disputa desmascara um processo disciplinar e de controle, a hegemonia de um grupo sobre o outro, estabelecida pelas diferentes tarefas entre os enfermeiros-docentes e os enfermeiros-assistenciais, na qual o docente, formalmente, responsabiliza-se pelas funções de coordenação e ensino, impondo-se como um trabalhador mais qualificado e aumentando, assim, as disputas de quem representa o poder e de quem a ele está subordinado.

O Programa de Integração Docente-Assistencial, um dos recursos utilizados pelo governo federal para aproximar o ensino e os serviços, tem sido apresentado como uma proposta de planejamento de saúde e educação para ajustar necessidades sociais e tecnológicas, sendo definido pelo MEC (BRASIL, 1981) como: "união de esforços em um processo de crescente articulação entre Instituições de Educação e de Serviços de Saúde adequados às necessidades reais $d a$ população, à produção de conhecimentos $e$ à formação de recursos humanos necessários, em um determinado contexto de prática de serviços de saúde e de ensino".

Portanto, segundo esse conceito, o programa faz parte de um processo que requer participação da sociedade, sendo que, através da realidade concreta, devem ser desenvolvidos os conteúdos acadêmicos e dos serviços, atendendo às necessidades da população, implicando na redefinição do sistema formador e do prestador de serviços com uma postura crítica sobre a realidade.

KAJIYAMA (1991) refere que a enfermagem brasileira tem demonstrado sua preocupação com a integração docente-assistencial, promovendo discussões a respeito dele nos Congressos Brasileiros de Enfermagem, nos Encontros Nacionais de Enfermeiros de Hospitais de Ensino e através da Rede IDA-Brasil.

CROSSETTI et al. (1985), OLIVEIRA (1987), PADILHA (1991) e EGRY; FONSECA (1994) referem que a IDA propicia o estabelecimento de objetivos comuns de trabalho entre instituição de ensino e de saúde, facilita a formação e utilização dos recursos humanos, produzindo conhecimento e melhoria na qualidade da assistência, ensino e pesquisa.

Entretanto, colocam como dificuldades a polarização dos enfermeiros em dois grupos (docentes e assistenciais), a filosofia e objetivos de trabalho divergentes entre as instituições envolvidas e a rigidez na definição nos papéis dos enfermeirosdocentes e assistenciais. Recomendam o estabelecimento de um processo de reflexão crítica que envolva todos os integrantes, uma definição de expectativas reais dos programas desenvolvidos e uma estratégia de participação dos setores componentes da integração, ou seja, instituição de ensino, instituição de saúde e comunidade.

A relação entre EE e HCPA, caracterizada como um programa docente-assistencial, a partir de 1988, adotou como marco referencial alguns pressupostos preconizados pelo MEC/SESU, em 1981, aparecendo o processo IDA como uma proposta de trabalho entre ambas as instituições mencionadas.

Temos por objetivo, neste estudo, apreender e analisar a dinâmica das relações do processo de integração docente-assistencial no HCPA desde a sua criação, relações essas que se conformam a partir da prática dos atores aí envolvidos e das políticas institucionais, econômicas e sociais, configurando-se, 
portanto, uma relação em movimento, uma prática institucional que se materializa através da EE, do HCPA, do Serviço de Enfermagem* e das ações das pessoas envolvidas nesse processo.

\section{PROCESSO DE INVESTIGAÇÃO ANÁLISE DE DADOS}

Este trabalho considera seu objeto de estudo como histórico, isto é, que se constrói e se transforma pelas ações, negociações, conflitos e tomada de consciência dos atores nele envolvidos em um dado tempo.

Parte, pois, de uma perspectiva históricoestrutural, entendendo a realidade estudada como um processo dinâmico, contraditório e em contínua transformação em que nada se constrói fora da história, uma totalidade dinâmica, produto da ação e da interação, da produção e da reprodução social. O conceito de totalidade procura as diferenças aí contidas e busca explicações que partem do particular para o geral e vice-versa, uma vez que não há ponto de partida definitivo, enfocando os conflitos e contradições no movimento do real, que geram mudança e transformação, ação e reação (DEMO, 1989).

Assim, conhecer a dinâmica do relacionamento entre EE-HCPA, no processo IDA, é visualizá-la como uma prática histórica, dinâmica, portanto, não cristalizada, mas estruturada por relações sociais, por atores em condições econômicas, politicas e culturais específicas, relações essas que se tornam concretas na prática inter-institucional, nas ações dos docentes e enfermeiros, nas concepções que têm sobre si, seu trabalho, seu lugar na sociedade.

$\mathrm{Na}$ investigação, foram utilizados como fonte primária atas e documentos da Congregação e Conselho Departamental da EE (período de 1950/ 1992), sendo que a coleta empírica dos dados usou como instrumentos entrevistas individuais com coordenadores da EE e do HCPA e entrevistas em grupo com enfermeiros-docentes e enfermeirosassistenciais, ancoradas em nossa experiência profissional.

O processo investigado teve como baliza alguns pressupostos da pesquisa-ação, mas não se caracterizou enquanto tal, embora THIOLLENT (1988) tivesse sido uma das fontes de inspiração e orientação metodológica $\mathrm{O}$ autor citado define pesquisa-ação como -"um tipo de pesquisa social com base empírica que é concebida e realizada em estreita associação com uma ação ou cam a resolução de um problema coletivo e no qual os pesquisadores e os participantes, representativos da situação ou do problema estão envolvidos d e modo cooperativo ou participativo" (p. 14)..

Assim, obter informações sobre a prática docente-assistencial no HCPA, sob a orientação desse tipo de pesquisa, poderá contribuir para implementar a referida prática, à medida em que os que a vivenciam terão oportunidade de refletir em conjunto sobre ela e, em conjunto, propor ações que possam solucionar os problemas aí envolvidos. Reafirmamos que o objetivo prático dessa pesquisa foi contribuir para desbloquear as informações sobre o processo estudado, divulgando diferentes visões a seu respeito.

Nas entrevistas individuais(11) e grupais(5) utilizamos a técnica de entrevista semi-estruturada, na qual as perguntas abertas e fechadas servem de orientação para o entrevistador e não como um controle de informações, possibilitando, desse modo, aos entrevistados falarem espontaneamente sobre o assunto (MINAYO, 1993).

Do ponto de vista operacional, os entrevistados foram pessoas escolhidas intencionalmente devido à relevância** que apresentavam na relação $\mathrm{EE}$ HCPA, sendo considerado a participação de todos os segmentos envolvidos na situação. O princípio de intencionalidade é adequado porque há um tratamento qualitativo da interpretação dos dados (THIOLLENT, 1988).

As entrevistas individuais foram feitas com: a diretora da EE; as chefias dos três Departamentos da EE(Enfermagem Médica e Cirúrgica; MaternoInfantil; Assistência e Orientação Profissional); a coordenadora da Pós-Graduação da EE; o presidente do HCPA; os vice-presidentes administrativo e médico do HCPA; a coordenadora do Grupo de Enfermagem do HCPA; uma docente ex-chefe de serviço e uma enfermeira de unidade.

As entrevistas em grupo com os enfermeiros docentes e assistenciais justificam-se por eles ocuparem posições e funções diferentes no processo IDA. Essa técnica é importante porque se presta ao estudo das representações de diferentes grupos profissionais e diferentes processos de trabalho (MINAYO, 1993).

* A Escola de Enfermagem é uma unidade daUFGRS, criada em 1950, tendo vinculação com o HCPA desde sua criação, em 1970, participando de sua organização. Essa vinculação estabelece entre as finalidades do hospital, a prestação de serviços, a cooperação nos planos de ensino da UFGRS e a participação dos docentes (Lei 5604/criação do HCPA, de 2 desetembro de 1970). (Brasil, 1970). O Serviço de Enfermagem do HCPA é denominado Grupo de Enfermagem, cuja coordenação encontra-se vinculado à Presidência do hospital.

Os entrevistados desempehanvam funções de chefia na Escola de Enfermagem e no HCPA 
O grupo foi composto por seis enfermeirosdocentes e seis enfermeiros-assistenciais diretamente relacionados com o programa IDA das duas instituições: uma docente ex-coordenadora do Grupo de Enfermagem do HCPA; uma docente coordenadora do Grupo de Enfermagem do HCPA em exercício; uma docente ex-chefe de serviço de enfermagem do HCPA; uma docente chefe de serviço de enfermagem do HCPA em exercício; uma docente do grupo IDA; uma docente assistente do Grupo de Enfermagem do HCPA; uma enfermeira assessora do Grupo de Enfermagem do HCPA; uma enfermeira chefe de unidade do HCPA; uma enfermeira de unidade do HCPA; uma enfermeira do grupo IDA; uma enfermeira supervisora de enfermagem do HCPA uma enfermeira presidente da Associação dos Enfermeiros do HCPA.

Para a análise dos depoimentos individuais e grupais, primeiramente, realizamos a transcrição das gravações, a releitura do material e organização do seu conteúdo.

$\mathrm{Na}$ classificação dos dados, é importante ter presente que o dado não existe por si mesmo, é construído através do questionamento que fazemos sobre o material obtido, com base na fundamentação teórica. Fizemos várias leituras das entrevistas, com o objetivo de identificar o que aparecia de relevante, as idéias centrais que queriam comunicar. Classificamos os pontos convergentes e divergentes, obtendo um conjunto de informações e de representações dos entrevistados sobre o processo estudado. Assim, emergiram dos dados as seguintes categorias de análise: a relação EE e HCPA; as representações sociais sobre a IDA; as relações de trabalho entre os enfermeiros docentes e assistenciais e as propostas de implementação para o processo.

Para aprimorar a interpretação dos depoimentos, realizamos, ainda, duas entrevistas com enfermeirosdocentes que tinham experiências diferentes do processo IDA em outras instituições de outros Estados (Mato Grosso e São Paulo), com o objetivo de relacionar e comparar com a situação investigada.

$\mathrm{Na}$ análise final, procuramos articular esses dados com o referencial teórico, pressupostos e objetivos do trabalho.

Nosso trabalho de mestrado, posteriormente, foi apresentado aos integrantes da IDA com o objetivo de devolver as informações obtidas e, para que o conhecimento resultante pudesse ser aproveitado como um instrumento para sua ação e transformação.

Pensamos que o resultado final possibilitou um maior conhecimento do processo IDA, permitindo a identificação dos principais problemas e a oportunidade de participação dos entrevistados nas soluções aventadas para essa prática no HCPA.

\section{A RELAÇÃO ESCOLA DE ENFERMAGEM E HOSPITAL DE CLÍNICAS DE PORTO ALEGRE}

Desde 1968, a EE discutia sua participação junto ao HCPA, que começou a funcionar, como já dissemos, a partir de 1970, vendo nesse hospital uma solução para a necessidade de campos de estágio das atividades práticas do curso.

Durante o período 1972-1983, conforme registro em atas da Congregação e do Conselho Departamental, a relação EE-HCPA foi operacionalizada através de um programa docenteassistencial, buscando transformações na prática de assistência e ensino, sendo que a concretização dessa filosofia de trabalho era possibilitada pelos enfermeiros-docentes que dirigiam o Grupo de Enfermagem.

\begin{abstract}
"Uma caracteristica que facilita manter essa IDA é a Escola estar obrigatoriamente nos cargos da administração de enfermagem". (Entrev. 5: coordenador)
\end{abstract}

A ocupação dos cargos de chefia do Grupo de Enfermagem pelos enfermeiros-docentes da EE, estabelecida no Regimento da Area Médica do HCPA, é uma característica que propicia o "trânsito" da EE para aplicar modelos de assistência de enfermagem, definindo o trabalho e o espaço desse grupo de profissionais. Essa obrigatoriedade regimental procura garantir a presença dos enfermeirosdocentes, mas ela, por si só, não viabiliza a proposta IDA. A coordenação é uma maneira de possibilitar à EE influenciar na organização do processo de trabalho da enfermagem, busca ser um facilitador para a atuação dos enfermeiros-docentes, dando condições de interferir nessa prática e favorecendo sua participação na vivência do cotidiano e das necessidades do HCPA.

Os primeiros momentos da relação EE-HCPA caracterizaram-se pela definição e organização do trabalho da enfermagem, sendo reconhecido o mérito da presença docente, colaborando na qualidade da assistência prestada pelo hospital até hoje.

"(...) um dos aspectos marcantes da qualidade do hospital, tem estado na estrutura da enfermagem e na qualidade dos profissionais que trabalham aqui. Isto se deve à Escola de Enfermagem". (Entrev. 1: coordenador)

Esse período inicial é considerado como de maior integração, conseguindo os docentes da $\mathrm{EE}$ conciliar as atividades de ensino, assistência e administrativas.

"Nesses longos anos, o periodo que no meu entendimento teve maior integração foi o do inicio". (Entrev. grupo: docente) 
De 1983 a 1993, o HCPA manteve seu crescimento e expansão, acarretando aumento das atividades necessárias para o seu funcionamento, mas os enfermeiros-docentes e enfermeiros-assistenciais começaram, então, a sentir dificuldades na operacionalização da integração inter-institucional.

Os entrevistados, quando questionados sobre as mudanças ocorridas na relação EE-HCPA, são unânimes em afirmar a transformação do processo IDA desde sua implantação.

Assim, da primeira fase, de uma maior integração, o processo IDA passou a ser vivido com dificuldades, divisões e disputas entre enfermeirosdocentes e enfermeiros-assistenciais, caracterizandose o seu retrocesso pela divisão entre os docentes, em enfermeiros-docentes do HCPA e enfermeirosdocentes da EE.

\section{"A questão é histórica em relação aos que estão lá e aos que estão aqui. Sempre houve uma indisposição em relação aos docentes do HCPA e os membros da EE". (Entrev. Grupo: docente)}

Os depoimentos apontam, também, uma inabilidade para implementar o referido processo. Se existe a intencionalidade de integração, a forma como ela se constrói não deve ser rígida, sendo necessário o constante enfrentamento de posições e modos diferentes, divergentes dessa prática de trabalho.

"Caracterizo como uma relação que busca um progresso, quer caminhar, as pessoas estão cheias de boas intenções, mas não se detiveram na forma como de direito avançar". (Entrev. 9: coordenador)

Esse breve resgate histórico evidencia o movimento e as alterações do processo IDA, no periodo focalizado, apontando para a inexistência de soluções ou formas definitivas e cristalizadas na sua implementação. Assim, o referido processo é percebido, em sua primeira década, como eficiente, transparecendo hoje, nos conflitos surgidos, a idéia de falta de integração entre os atores e instituições envolvidos, a fragmentação desse processo em pessoas, práticas e poderes diferentes, tentando impor-se uns sobre os outros.

\section{REPRESENTAÇÕES SOBRE A INTEGRAÇÃO DOCENTE-ASSISTENCIAL}

Os entrevistados ao responderem a pergunta: o que é IDA? revelam a incorporação do conceito proposto pelo MEC/SESU, colocando suas idéias como respostas genéricas ou como uma elaboração teórica construída pelas informações recebidas, discutidas e vividas no dia-a-dia da relação inter-institucional.

\section{"IDA seria um intercâmbio de um efetivo da universidade com o hospital. Uma reciprocidade de conhecimento $e$ de crescimento para as pessoas." (Entrev. Grupo: enfermeira)}

Ainda relacionado a essa definição, os docentes introduzem a participação do aluno e percebem a atividade docente como um vínculo que extrapola o estágio, a idéia de estar dentro do hospital, participando das tarefas diárias da enfermagem.

"Nessa relação entre docente e assistente também existe o aluno. Ele deve estar integrado." (Entrev. Grupo: docente)

Do mesmo modo, os coordenadores acrescentam a importância do aspecto formal, a necessidade de padrões claramente definidos das ações com o objetivo de garantir uma organização e administração do processo de integração entre as duas instituições.

"A IDA é caracterizada por principios, é um tipo de ajuda mútua em que estão envolvidas duas instituições no mínimo com um objetivo comum. (...) Nela deve estar descrito dentre as partes, qual o compromisso de ambos, como pretendem desenvolver essa atividade." (Entrev. 3: coordenador)

No entanto, os entrevistados, ao falarem como pensam que a IDA deveria acontecer, mostram uma expectativa idealizada, em que aquela surge como uma realidade alheia ao concreto da relação EEHCPA. Falam de IDA como uma relação harmônica, uma utopia, uma proposta ideal.

"(...)Imagino que seja compartilhar, seja dividir, seja dar e receber. (...) IDA seria um casamento entre a $E E$ e o HCPA". (Entrev. 10: docente)

Entretanto, no concreto, transparece a dificuldade de sua operacionalização que atende a diversas e diferentes necessidades, com o predomínio de uma categoria sobre outra, revelando-se "o problema" da integração.

"Acho que é muito difícil, de certa maneira é uma coisa utópica. É uma proposta que se fez, entendendo que seria o ideal. Nós vivemos no real." (Entrev. Grupo: docente)

Umas das dificuldades identificadas para articular a IDA como um processo efetivo de integração é a dicotomia instituída que envolve duas instituições diferentes que mantêm suas características e seus interesses divergentes. 
"Estou no HCPA para prestar assistência aos pacientes em primeiro lugar. Também, vou auxiliar em relação aos alunos. Vão estar na minha unidade, mas a minha finalidade é prestar assistência. E o professor, enquanto está aqui, a finalidade é ensinar o aluno." (Entrev. Grupo: enfermeira)

A universidade dá prioridade ao ensino e o hospital tem como meta primeira o atendimento dos pacientes, tendo ambos entre os seus objetivos um trabalho conjunto, definido através do processo IDA que, na prática, aparece separado, distanciado, desconhecido, pois as ações são unilateralizadas em papéis, pessoas e poderes diferentes, tentando prevalecer uns sobre os outros. Desse modo, a dicotomia institucionaliza-se como uma regra desse processo e, a partir dela, desencadeiam-se as demais dificuldades de integração.

Essa dicotomia institucionalizada evidencia a divisão entre os enfermeiros-docentes e os enfermeiros-assistenciais.

"A porta do hospital está mais aberta do que a porta da EE. Os professores aqui encontram a porta aberta onde quiserem. O enfermeiro já sabe que aqui é lugar de professor e aluno. Agora, na EE, já não vejo assim, lá é lugar dos professores. Tu vais lá se fizerem um convite ou outra coisa, mas a porta não está aberta." (Entrev. Grupo: enfermeira)

Do mesmo modo, os enfermeiros-docentes sentem a não receptividade dos enfermeirosassistenciais quando estão nas unidades de internação.

"Agora, como professora sinto que não posso ir às unidades". (Entrev. Grupo: docente)

O sentimento de dificuldade de acesso é, pois, recíproco entre enfermeiros-docentes e enfermeiros-assistenciais. Há uma resistência devido às suas práticas diferentes, aos interesses divergentes, às formas de utilização dos espaços institucionais, às divisões de papéis e de poder entre ambos, explicados pela dicotomia institucionalizada, na qual as caracteristicas peculiares prevalecem, criando obstáculos para a integração, uma idéia de "não trabalho em equipe".

Entretanto, entendemos que a articulação pode ser facilitada se houver clareza do processo IDA entre a EE e o HCPA: o que as instituições e os atores esperam desse trabalho coletivo? quais os papéis e as funções de cada integrante do programa? quais as diferenças? como compartilhar, somar e integrar essas diferenças?
Esses questionamentos devem permanecer abertos e presentes no processo investigado, promovendo as mudanças e entrosamentos necessários e possíveis.

Outra dificuldade na operacionalização das relações de trabalho entre interinstitucionais é a sobrecarga dos enfermeiros-docentes vinculados ao processo IDA.

A EE e o HCPA cresceram e se desenvolveram nesses anos. Conseqüentemente, aumentaram as exigências de trabalho dos enfermeiros-docentes para atender as demandas das duas instituições que apresentam características e necessidades diferentes.

"(...) não tens como fazer todos os compromissos dentro do hospital e viver a universidade como um todo". (Entrev.grupo: docente)

Os enfermeiros-docentes da IDA acumulam as tarefas das duas instituições e, na impossibilidade de assumirem a totalidade dos compromissos, priorizam as atividades da EE ou do hospital.

O processo IDA não é uma filosofia de trabalho que orienta e direciona a maioria das ações da EE, é uma proposta direcionada para a vinculação com o HCPA. O trabalho dos enfermeiros-docentes no hospital é mais um âmbito de ação da EE, junto com as atividades de graduação, pós-graduação e extensão. Assim, os enfermeiros-docentes percebem-se sobrecarregados nas suas atividades porque as tarefas são acumuladas, reflexo de relações de trabalho não integrado e dividido. Essas diferenças , também, refletem uma universidade dividida em unidades, em disciplinas, uma sociedade dividida em classes, em que se atribuem valores diferentes a diferentes tipos de trabalho "e a diferentes cargos, produzindo desigualdades.

A disputa entre enfermeiros-docentes e enfermeiros-assistenciais pelos cargos diretivos do Grupo de Enfermagem, garantidos pelo Regimento da Area Médica aos docentes da universidade, tem interferido bastante no referido processo. Essa disputa traduz-se numa luta de poder, pois os enfermeiros-docentes parecem ter mais status e privilégios, enquanto os enfermeiros-assistenciais estão subordinados àqueles hierarquicamente e têm sua autoridade reduzida dentro do hospital.

"A queixa dos enfermeiros sempre foi $e$ acho que ainda continua sendo que as docentes dão pouca assessoria nas unidades, que ficam mais com a arte administrativa. Outra queixa é que elas gostariam de ascender na sua carreira profissional, ter o cargo de chefe de serviço e, futuramente, até de coordenadora. Acho que essa aspiração é válida, apesar de eu não concordar com ela". (Entrev. 7: coordenadora) 
Como procuramos mostrar, o poder é uma prática exercida e disputada no processo IDA entre os enfermeiros-docentes e os enfermeirosassistenciais, tendo seu exercício trazido à enfermagem do HCPA sustentação profissional e qualidade na assistência prestada. Ao mesmo tempo, apresenta aspectos negativos quando reproduz a hegemonia dos enfermeiros-docentes sobre os enfermeiros-assistenciais, sendo usado como autoridade, como uma forma de imposição para comandar esses últimos e submetê-los a um poder decisório maior na relação, restringindo-lhe as ações.

Em suma, existe uma relação de força entre os enfermeiros-docentes e os enfermeirosassistenciais, que interfere na relação e no processo IDA entre a EE e o HCPA, traduzindo-se esses conflitos ora em mudanças e força política dos enfermeiros-docentes e assistenciais ora em controle de um grupo sobre o outro, podendo emperrar as transformações possiveis dessa prática de integração.

\section{AS RELACÕES DE TRABALHO E SUAS REPRESENTAÇÕES}

Reiteramos que o processo IDA analisado reflete uma relação de trabalho entre enfermeirosdocentes e enfermeiros-assistenciais, disputando, exercendo e assumindo papéis e posições diferentes, conforme sua prática, seu status e seu poder.

Os entrevistados caracterizam essas relações como competitivas, desgastantes e não profissionais, referindo diversos motivos para que essa relação aconteça com divergências e resistências.

"As nossas relações não são profissionais, são pessoais, são de camaradagem". (Entrev. Grupo: docente)

Uma das características percebidas é a organização dos enfermeiros-assistenciais, enquanto grupo profissional, questionando a participação e representatividade dos enfermeiros-docentes.

"É uma relação bem diferente porque hoje as enfermeiras são bem mais organizadas". (Entrev. Grupo: docente)

Outra questão apontada relaciona-se ao crescimento do HCPA, que aumentou o quantitativo de enfermeiros-assistenciais para o atendimento das demandas do hospital, sendo admitidos profissionais graduados em outras instituições de ensino não oriundos da $\mathrm{EE}$, mudando a relação inicial de professor-aluno para uma relação patrão-empregado.

"No início era um tipo de relacionamento, porque as primeiras turmas de enfermagem iam para lá em massa. A competição não era tão grande, portanto se estabelecia até uma relação de professor-aluno. Depois, o HCPA aumentou e vieram outros profissionais de outras escolas. (...)estabelecendo-se uma relação mais diferenciada." (Entrev. 9: coordenadora)

O desconhecimento do processo IDA e das pessoas que dele participam, seus papéis, seus objetivos, como trabalhar, bem como a centralização na atividade de coordenação do Grupo de Enfermagem tem interferido, também, na forma de relação entre os enfermeiros-docentes e os enfermeiros-assistenciais. As relações de trabalho aparecem hierarquizadas, filtrando as comunicações e permitindo a construção de idéias falsas em termos de subordinação e dominação.

"Existe uma dificuldade na relação. (...) as enfermeiras gostariam de conhecer os professores, pelo menos saber o nome do professor que seria eleito ou seria candidato." (Entrev. Grupo: enfermeira)

A separação das atividades assistenciais, administrativas e docentes, hierarquizando as relações de trabalho, nas quais os enfermeirosassistenciais encontram-se subordinados aos enfermeiros-docentes, é outra questão percebida como um fator de disputas ou privilégios entre os mesmos.

" (...) mas é muito forte o sentimento da enfermeira do hospital em relação ao fato de que ela exerce a profissão, enquanto que as docentes da Escola exercitam a atividade de administração ou uma atividade docente." (Entrev. 1: coordenador)

Outra questão identificada pelos entrevistados é o surgimento de mecanismos de resistência dos enfermeiros-assistenciais em relação à coordenação dos enfermeiros-docentes e, conseqüentemente, interferindo nas relações de trabalho e no processo IDA.

" (...) a gente sente essa dificuldade porque existe uma resistência organizada, montada, estruturada, consistente em relação às coisas que os enfermeiros acreditam, até que ponto eles vão suportar e o quanto eles vão aceitar as coisas. (...) tu vais solicitar algo para as gurias do nosso serviço e dizem não. E, é um não bem categórico. (...) os enfermeiros são bem claros nas colocações quando não querem as coisas, eles te boicotam a reunião inteira se quiserem." (Entrev. Grupo: enfermeira) 
Essas declarações retratam os enfermeirosassistenciais resistindo à chefia dos enfermeirosdocentes, disputando seu espaço no processo de trabalho e questionando a construção dessa prática. São subordinados exercitando seu poder, demonstrando e valorizando o saber oriundo de sua prática.

O boicote nas reuniões, referido, discordando, sendo cordiais, apresenta-se como mecanismos de oposição utilizados na medida que se percebem limitados em sua ascensão profissional e em sua autoridade, submetidos ao comando dos enfermeirosdocentes. Entretanto, essa resistência ao longo dos anos da relação entre a EE e o HCPA parece-nos que tem se revestido em possibilidade de transformação desse trabalho coletivo, produzindo mudanças na assistência de enfermagem e possibilitando prestígio e autonomia desses profissionais dentro do HCPA.

A resistência mostra o caráter relacional do poder, pois implica em luta, uma relação de força entre os enfermeiros-docentes e assistenciais, aparecendo como uma forma de agir juntos para estabelecer com argumentos e debates, uma reflexão necessária para ajuste/reajuste no processo IDA e nas relações de trabalho ali estabelecidas.

FOUCAULT (1992) refere que existem formas de poder em constante transformação. Poder é uma prática social, funcionando como uma rede de mecanismos a que nada ou ninguém escapa. Assim, poder não é algo que se detém como uma coisa. Não existe de um lado os que têm poder e do outro aqueles que não o têm. Existem práticas ou relações de poder. Poder é algo que se exerce. O caráter relacional do poder implica que as próprias lutas contra o seu exercício não possam ser feitas de fora, pois nada está isento de poder. Poder é luta, afrontamento, relação de força. Não é um lugar que se ocupa, nem objeto que se possui. Ele se exerce e se disputa. E não é uma relação unilateral, pois nessa disputa ou se ganha ou se perde. Assim, o poder é uma prática, que se faz exercitando-o. Tem caráter positivo quando produz e transforma e negativo quando exerce sua função repressiva.

Operacionalizar melhor a integração é enfrentar e gerenciar os conflitos do trabalho e das relações que dele decorrem, entendendo que as relações são construídas com momentos de maior ou menor abertura, participação e alianças.

\section{OUTRA HISTÓRIA: O PROCESSO IDA E A PRATICA ASSISTENCIAL}

Independente dos obstáculos e problemas para a efetivação de uma relação menos conflituosa entre a $\mathrm{EE}$ e 'o HCPA, os entrevistados percebem as intenções para efetivar a integração e têm caracterizado essa prática como contendo avanços e retrocessos, influenciando a assistência de enfermagem na qual os enfermeiros-docentes e assistenciais se organizaram como grupo de trabalho.

Esse intercâmbio entre a EE e o HCPA tem interferido na definição e organização do trabalho da enfermagem, colaborando na qualidade do cuidado prestado no hospital, revestindo-se, tal fato, também, em prestígio e sustentação desse grupo dentro e fora da estrutura hospitalar.

"(...) um dos aspectos marcantes da qualidade do hospital, tem estado na estrutura da enfermagem e na qualidade dos profissionais que trabalham aqui. Acho que isto se deve à Escola de Enfermagem." (Entrev. 1: coordenador)

Parece-nos que o resultado dessa articulação inter-institucional é positivo. Os enfermeirosdocentes, os enfermeiros-assistenciais e os dirigentes reconhecem a importância da proposta IDA, que deve ser compartilhada em ações que visam a transformações na prática assistencial e de ensino e apontam alternativas para a construção e implementação desse trabalho, sugerindo uma participação dos enfermeiros-docentes com um vínculo que extrapole as atividades da coordenação do Grupo de Enfermagem e as atividades curriculares de estágio. Propõem a presença dos enfermeiros-docentes nas unidades de internação, identificando conjuntamente os interesses e as necessidades para estabelecerem programas de trabalho.
"A Escola deveria estar dentro do hospital com os professores mais presentes. Vamos fazer uma campanha: adote uma unidade." (Entrev. Grupo: enfermeira)

Enfatizam o papel de assessor para a atuação dos docentes no processo IDA, ou seja, auxiliar tecnicamente nos programas e nas pesquisas surgidas a partir da prática.

\section{"O que precisava realmente é o professor com papel de assessor. (...)estar nas unidades, vendo as dificuldades no assistir com os alunos e vou contribuir naquilo." (Entrev. Grupo: docente)}

Assim, a construção da IDA como uma proposta de trabalho compartilhado é vista como sendo facilitada através de um processo democrático de participação em todos os âmbitos de ação.

"Não existe um outro caminho se não a chefia participativa, sendo a solução para a grande maioria dos problemas." (Entrev. Grupo: enfermeira) 
Contudo, entendemos que esse processo participativo não deve ser utilizado como uma maneira de acomodar os conflitos ou de fazer arranjos para atender interesses pessoais, mas como participação necessária de todos os seus integrantes em todas as instâncias em que as responsabilidades e as decisões para operacionalizar a integração possam ser deliberadas conjuntamente em prol dos interesses coletivos dos atores, das instituições e dos pacientes.

\section{CONSIDERAÇÕES FINAIS}

A pesquisa que buscamos sintetizar nesse artigo foi realizada em 1994, oriunda do nosso trabalho de mestrado e, pensamos que permitiu esclarecer melhor os problemas da situação investigada. Desse modo, processo de integração docente-assistencial entre a EE e o HCPA aparece construído e reconstruído cotidianamente pelos atores e instituições nele envolvidos.

Esse trabalho coletivo é visto, inicialmente, nas entrevistas, como uma real integração, sendo que as dificuldades, divisões e disputas atuais são vividas como conflitos que parecem cristalizar as relações ali estabelecidas, impedindo a sua renovação.

No conjunto, as transformações ocorridas, a partir de 1989, são identificadas como avanços e recuos devido à organização dos enfermeirosassistenciais, alterações na estrutura organizacional do hospital e na assistência de enfermagem prestada, no crescimento da EE e do HCPA e na manutenção da dicotomia institucional, traduzindose na idéia de trabalho desintegrado.

A autonomia conquistada pelos enfermeiros no exercício de suas atividades e a qualidade e reconhecimento da assistência prestada pelo HCPA traduzem-se como avanços. As divisões entre os enfermeiros-docentes, sua pouca participação e renovação no processo IDA, centrando suas tarefas no papel administrativo, aumentam as disputas de poder entre eles e os enfermeiros-assistenciais, representando o retrocesso do referido programa.

Freqüentemente, o processo investigado aparece idealizado, aos que dele participam, sendo percebido como se não houvesse atores e relações, transparecendo também inabilidades para operacionalizá-1o, em que os dogmas de "assim deve ocorrer" ou "é assim" dificultam o fazer/refazer diário desse trabalho.

A EE e o HCPA mantêm suas características próprias, os atores estão divididos de acordo com o trabalho que executam e as posições que ocupam.
Os enfermeiros-docentes que participam da IDA sentem-se sobrecarregados nas suas atividades, pois atendem demandas de trabalho das duas instituições. Centram suas atividades na coordenação do Grupo de Enfermagem de que participam apenas treze docentes, que valorizam esse âmbito de ação profissional que lhes dá prestígio, reforçando seu poder.

Os enfermeiros-assistenciais subordinados hierarquicamente aos enfermeiros-docentes percebem a autoridade desses últimos como uma restrição ao seu trabalho, predominando entre eles relações competitivas. Dessa forma, o processo IDA apresenta-se de modo positivo, enquanto grupo de profissionais com parcelas de poder para mudar práticas de ensino e assistenciais e, negativamente, enquanto domínio de um grupo sobre outro.

As relações hierarquizadas reforçam a idéia de desintegração, quando usadas para manutenção de prestígio, negando o potencial transformador da luta pelo poder.

Independente dos conflitos existentes, o processo IDA possibilitou, para a enfermagem do HCPA, a conquista de seu papel profissional, prestígio e autonomia relativa no exercício de seu trabalho, sendo apontado como alternativas para implementá-lo: o papel de assessor dos enfermeiros-docentes e sua participação centrada nas unidades de internação, o comprometimento da universidade com esse trabalho e uma administração participativa.

Concluímos que a integração implica em diferentes formas de acontecer, não existindo uma compreensão única para o processo IDA. Integrar supõe estar aberto ao diálogo e ao debate, aceitar as divergências para que os atores dessa prática possam construí-la/ reconstruí-la em novos patamares.

\section{REFERÊNCIAS BIBLIOGRÁFICAS}

BRASIL, Leis etc. Lei n ${ }^{\circ} 5604$ de 02 de setembro de 1970 . Autoriza o Poder Executivo a criar a empresa pública Hospital de Clínicas de Porto Alegre e dá outras providências. Diário Oficial da República Federativa do Brasil, Brasília, 2 set. 1970.

Ministério da Educação e Cultura. Secretaria do Ensino Superior. Programa de Integração Docente-Assistencial IDA. Brasília, MEC/SESU/CCS, 1981. 32 p. Cadernos da Ciência da Saúde, n.3.

CROSSETTI, M. da G. O. et al. Relato de uma experiência de integração docente-assistencial no HCPA. /Trabalho apresentado no Encontro Nacional de Enfermagem de Hospitais de Ensino, Fortaleza, s/d./ 
DEMO, P. Metodologia científica em ciências sociais. 2. ed. São Paulo, Atlas, 1989

EGRY, E. Y.; FONSCECA, R. M. G. S. da. Dimensão pedagógica da integração docente-assistencial como estratégia de intervenção no saber/fazer em saúde coletiva. Saúde Déb., n.42, p.16-22, 1994.

FOUCAULT, M. Microfísica do poder. 10 ed. Rio de Janeiro, Graal, 1992. p. 7-27: Introdução: por uma genealogia do poder.

HOSPITAL DE CLÍNICAS DE PORTO ALEGRE. Regimento da Área Médica do Hospital de Clínicas de Porto Alegre. Porto Alegre, 1975.

KAJIYAMA, H. Estudo das atividades do docente de enfermagem no programa de integração docenteassistencial. São Paulo, USP, 1991. Tese (Doutorado) - Escola de Enfermagem, Universidade de São Paulo.
MINAYO, M. C. S. O desafio do conhecimento: pesquisa qualitativa em saúde. 2. ed. São Paulo, HUCITEC ABRASCO, 1993.

OLIVEIRA, C. C. Modelos de integração docente-assistencial In: ENCONTRO NACIONAL DE ENFERMEIROS DE HOSPITAL DE ENSINO, 5, Florianópolis, 1987. Anais. Florianópolis, UFSC, 1987. p.101-22.

PADILHA, M. I. C. S. Análise crítica das causas de integração e/ ou desistengração docente-assistencial na enfermagem. Rev. Gaúcha Enf., v.12, n.1, p.33-'7, 1991.

SILVA, G. B. Enfermagem profissional: análise crítica. São Paulo, Cortez, 1986.

THIOLLENT, M. Metodologia de pesquisa-ação. 4.ed. São Paulo, Cortez, 1988. 